\title{
Dexamethasone Stimulates Vitamin K-Dependent Carboxylase Activity in Neonatal Rats and Cultured Fetal Hepatocytes
}

\author{
REIDAR WALLIN AND SUSAN M. HUTSON \\ Departments of Medicine and Biochemistry, The Bowman Gray School of Medicine, Wake Forest University, \\ Winston-Salem, North Carolina 27103
}

\begin{abstract}
Carboxylation of vitamin K-dependent clotting factors may be a key regulatory element in output of these proteins from liver to blood in the developing neonate. We have investigated the effect of hormones and growth factor on the vitamin K-dependent carboxylation system in neonatal rats and cultured fetal hepatocytes. Of the hormones and growth factor tested, only dexamethasone had a significant effect on the system. When dexamethasone was administered to newborn rats, there was a delayed response that produced significant enhancement of carboxylase activity $6 \mathrm{~d}$ after injection of the drug. A similar delayed response to the drug could also be demonstrated in cultured fetal hepatocytes. When cultured in the presence of 0.1-1 $\mu \mathrm{M}$ dexamethasone, cellular carboxylase activity was little affected by the drug the first $2 \mathrm{~d}$ of culture but the activity was increased more than threefold by $4 \mathrm{~d}$ in culture. Microsomal membranes from neonatal rat livers and fetal hepatocytes treated with dexamethasone showed enhanced vitamin $\mathrm{K}$-dependent ${ }^{14} \mathrm{C}$ labeling of the factor $X$ membrane precursor pool. Enhanced labeling of the factor $\mathrm{X}$ membrane precursor pool has also been demonstrated in rats and HepG2 cells treated with warfarin. The data suggest that 1 ) $\gamma$-carboxylation of clotting factors is regulated by glucocorticoids in the developing liver, and 2) dexamethasone stimulates intracellular $\gamma$-carboxylation of the factor $X$ precursor by a mechanism that currently is unknown. (Pediatr Res 30: 281-285, 1991)
\end{abstract}

\section{Abbreviations}

TAT, tyrosine aminotransaminase

Vitamin $K_{1} H_{2}$, the fully reduced hydroquinone form of vitamin $\mathbf{K}_{1}$

CHAPS, 3-[(3-cholamidopropyl)dimethylammonio]-1-propanesulfonic acid

$T_{3}$, triiodothyronine

Vitamin $\mathrm{K}$ deficiency has traditionally been associated with bleeding complications in the newborn (1). Recent reports (2-5) have documented, however, that fetal and neonatal livers are not normally deficient in vitamin $\mathrm{K}$ because PIVKA (Protein Induced in Vitamin K Absence) factors cannot be detected in most fetal and newborn blood plasmas. Bleeding problems in newborns with sufficient liver vitamin $\mathrm{K}$ stores are more unclear These problems are seen most and are usually more severe in

Received January 3, 1991; accepted May 13, 1991.

Correspondence and reprint requests: Reidar Wallin, Rheumatology, Department of Medicine, The Bowman Gray School of Medicine, 300 South Hawthorne Road, Winston-Salem, NC 27103.

Supported by Grant HL-42650 from the National Institutes of Health. the premature infant where periventricular and intraventricular bleeding can be a serious problem (6). The incidence of this bleeding varies inversely with gestational age which suggests that maturational factors are involved (6).

To get insight into the etiology of neonatal bleeding problems it is necessary to understand the processes involved in maturation of the hemostatic system. This includes an understanding of the vitamin K-dependent carboxylation system in the developing liver that is responsible for postribosomal $\gamma$-carboxylation of clotting factors, II, VII, IX, X, protein S, and protein $\mathbf{C}(7,8) . \gamma$ Carboxylation of these clotting factors results in their $\mathrm{Ca}^{2+}$ binding properties which are essential for normal hemostasis (9). The vitamin K-dependent carboxylation system consists of the vitamin K-dependent carboxylase, an integral membrane protein of the endoplasmatic reticulum (10), and enzymes involved in reduction of vitamin $\mathrm{K}$ to its active cofactor form, vitamin $\mathrm{K}$ hydroquinone (11). In a previous report, we provided evidence for an ongoing maturation process of the vitamin K-dependent carboxylation system in fetal and neonatal rats (7). In this report, we have focused on regulation of vitamin K-dependent carboxylation by hormones and growth factors. Data are presented that demonstrate that dexamethasone stimulates vitamin K-dependent carboxylation in neonatal livers and fetal hepatocytes in culture. Dexamethasone is also shown to enhance intracellular $\gamma$-carboxylation of the factor X precursor.

\section{MATERIALS AND METHODS}

Treatment of Neonatal Rats with Hormones. Pregnant Sprague-Dawley rats (12 d pregnant) were purchased from Zivic Miller Laboratories (Zalinople, PA) and brought to our animal facilities where they gave birth to their offspring. On $\mathrm{d} 1$ after birth ( $24 \mathrm{~h}$ after delivery), the rat litters were divided into three groups with eight litters in each group. Each neonatal rat in group A received $10 \mu \mathrm{g}$ of dexamethasone per gram body wt as an intraperitoneal injection in saline. Each neonatal rat in group B received $40 \mathrm{mU}$ of insulin as an intraperitoneal injection in saline. Group C was the control group, and each neonatal rat in this group was given an equivalent amount of saline. The neonatal rats stayed with the mothers until they were killed on $\mathrm{d} 2$, 3,5 , and 7 after birth (two litters were killed on each day). The livers were removed from the neonatal rats. The pooled livers from two litters were washed in ice-cool saline and were used for preparation of liver microsomes as described below.

Preparation and Culture of Fetal Hepatocytes. Pups from 18d pregnant rats were aseptically removed from the uterus and killed by cervical dislocation. The pup livers were surgically removed, placed in Dulbecco's $\mathrm{Ca}^{2+}-$ and $\mathrm{Mg}^{2+}$-free PBS (PBS "A"), and finely minced with a scalpel. Approximately $3 \mathrm{~g}$ of minced liver tissue was placed into a $250-\mathrm{mL}$ conical flask containing $20 \mathrm{~mL}$ of PBS "A" and allowed to shake at $37^{\circ} \mathrm{C}$ for $10 \mathrm{~min}$. The supernatant was discarded, and the wash was 
repeated. The tissue was then washed two times with PBS "A" containing $0.5 \mathrm{mM}$ EGTA. Hepatocytes were prepared by digestion with $20 \mathrm{~mL}$ of Hanks' $\mathrm{Mg}^{2+}$-free balanced salt solution containing $5 \mathrm{mM} \mathrm{CaCl}_{2}, 0.05 \%$ collagenase, and $0.1 \%$ hyaluronidase (wt/vol) at $37^{\circ} \mathrm{C}$ for $60 \mathrm{~min}$. The remaining cloudy suspension was filtered through $150-\mu \mathrm{m}$-pore-size cloth to remove cell clumps and undigested material. The filtrate was centrifuged $(200 \times g$ for $2 \mathrm{~min}$ ), and the cell pellet was washed once with FCS and washed twice with cell culture medium (arginine-free Eagle minimal essential medium supplemented with $0.6 \mathrm{mM} \mathrm{L-}$ ornithine, $10 \%$ FCS, $1 \%$ [vol/vol] of Gibco's antibiotic-antimycotic mixture, and $1 \%$ kanamycin sulfate). In some experiments, the FCS was charcoal treated before use. The cells were plated in $100-\mathrm{mm}$ tissue culture dishes at a density of $2 \times 10^{5}$ cells/ $\mathrm{cm}^{2}$. The dishes were incubated in an atmosphere of air (95\%) and $\mathrm{CO}_{2}(5 \%)$. After $24 \mathrm{~h}$, the medium was changed to remove cellular debris and contaminating erythrocytes.

Treatment of Fetal Hepatocytes. After the first $24 \mathrm{~h}$ in culture, cultured fetal hepatocytes were treated with dexamethasone $(0.1$ and $1 \mu \mathrm{M})$ and insulin $(10 \mathrm{nM})$ for $5 \mathrm{~d}(\mathrm{~d} \mathrm{1-5})$. Cells were harvested on $\mathrm{d} 2,3,4$, and 5 . The medium was replaced daily with fresh medium containing hormone. In a parallel set of experiments dexamethasone was added only on $d 1$. For the remaining part of the experimental 5-d period, the medium was replaced each day by fresh medium containing no hormone. The effect of warfarin was also investigated by adding the drug ( 50 $\mu \mathrm{M}$ ) to the cells on $\mathrm{d} 1$ followed by harvesting on $\mathrm{d} 2,3,4$, and 5 . Fresh medium added on d 2, 3, and 4 did not contain any warfarin. Cells were removed from the dishes with a cell scraper. Microsomes and cytosol were prepared as described below.

Isolation of Microsomes. Microsomes from livers. Livers were homogenized in $250 \mathrm{mM}$ sucrose- $25 \mathrm{mM}$ imidazole (pH 7.2) containing $5 \mathrm{mM}$ benzamidine and $1 \mathrm{mM}$ diisopropyl fluorophosphate (buffer A) as described (7). The homogenate was centrifuged twice at $10000 \times g$ for $10 \mathrm{~min}$ and then at 100000 $\times g$ for 60 min to obtain a microsomal pellet.

Microsomes from fetal cells. Cells removed from the tissue culture dishes were suspended in buffer A, washed three times by centrifugation, and resuspended in this buffer. For preparation of microsomes, $30 \times 10^{6}$ to $50 \times 10^{6}$ cells were used. The final washed cell pellet was resuspended in $2 \mathrm{~mL}$ of buffer $A$ and sonicated on ice for three 10 -s intervals at $50 \%$ duty cycle by using a Branson Sonifier model 250. Sonicated cells were centrifuged at $10000 \times g$ for $10 \mathrm{~min}$. Microsomal particles from the sonicated fetal cells were obtained as a pellet after centrifugation of the $10000 \times g$ supernatant at $100000 \times g$ for $60 \mathrm{~min}$. The supernatant (cell cytosol) was used for determination of TAT activity.

Enzyme Activities. Vitamin K-dependent carboxylase activity was measured as ${ }^{14} \mathrm{CO}_{2}$ incorporated into the synthetic peptide carboxylase substrate FLEEL (peptide carboxylation) and also as ${ }^{14} \mathrm{CO}_{2}$ incorporation into endogenous microsomal protein (protein carboxylation). Both assays were carried out as described in Ref. 7 with washed microsomal membrane fragments as the enzyme source. For preparation of these membrane fragments, microsomes were suspended in a Dounce homogenizer in 25 $\mathrm{mM}$ imidazole- $0.5 \%$ CHAPS- $5 \mathrm{mM}$ benzamidine- $1 \mathrm{mM}$ diisopropyl fluorophosphate $(\mathrm{pH} 7.2$ ) (buffer B) and subjected to centrifugation at $100000 \times g$ for $60 \mathrm{~min}$. The pellet that harbored the membrane fragments was resuspended in buffer B for determination of carboxylase activity (12). Carboxylase activity was triggered by addition of chemically reduced vitamin $\mathrm{K}_{1} \mathrm{H}_{2}$ to the test system (11). TAT activity was measured as described by Granner and Tomkins (13). One unit of enzyme activity was defined as the quantity of enzyme that catalyzed formation of 1 mmol of $p$-hydroxyphenylpyruvate per minute at $37^{\circ} \mathrm{C}$.

Prothrombin Precursor. The microsomal concentration of the prothrombin precursor was measured by immunodot blotting as described (12). Purified rat prothrombin was used to establish the standard curve for the precursor concentration.
SDS-PAGE and Fluorography of ${ }^{14} C$-labeled Carboxylase Substrates. Endogenous carboxylase protein substrates in microsomal membrane fragments were ${ }^{14} \mathrm{C}$-labeled in vitro as described (12) and subjected to SDS-PAGE in $10 \%$ gels for fluorography (12).

Materials. Vitamin $\mathrm{K}_{1}$, warfarin, dexamethasone, insulin, epidermal growth factor, and platelet-derived growth factor were purchased from Sigma Chemical Co. (St. Louis, MO). IL-1 was a gift from Dr. Charles McCall, The Bowman Gray School of Medicine, (Winston-Salem, NC). Vitamin $\mathrm{K}_{1}$ was reduced to vitamin $\mathrm{K}_{1} \mathrm{H}_{2}$ as described by Sadowski et al. (14). The pentapeptide carboxylase substrate FLEEL was purchased from Vega Fox Biochemicals Division (Tucson, $\mathrm{AZ}) . \mathrm{NaH}^{14} \mathrm{CO}_{3}(60 \mathrm{mCi} /$ mmol) was from Amersham Corp. (Arlington Heights, IL). Protein was measured by using the Bio-Rad protein assay. Antisera against rat prothrombin and rat factor $\mathrm{X}$ were obtained as described (12). Statistical analysis was done by applying a $t$ test.

\section{RESULTS}

Fetal hepatocytes. The preparation of fetal hepatocytes, when cultured for $24 \mathrm{~h}$ in an arginine-free medium, was found to be essentially free from contaminating hemopoietic cells. Based on Tryphan blue exclusion, the fetal hepatocyte preparation was also shown to contain greater than $95 \%$ viable hepatocytes. The effect of dexamethasone on vitamin K-dependent carboxylation in these cells in culture is shown in Figure 1. On $\mathrm{d} 1$ (see Experimental Section), the fetal cell cultures were treated with either $0.1 \mu \mathrm{M}$ dexamethasone (open bars), $1 \mu \mathrm{M}$ dexamethasone (diagonal bars), or saline (solid bars), and this hormonal treatment was continued for 4 more $d$ in culture (d 2-5). Fresh medium with hormones was added to the cells on each day. On each day, cells were harvested and vitamin $\mathrm{K}$-dependent carboxylase activity was determined in microsomal membranes isolated from the cells. As seen in Figure 1, dexamethasone stimulated vitamin $\mathrm{K}$-dependent carboxylase activity in cultured fetal hepatocytes. After $1 \mathrm{~d}$ in culture (Fig. 1, d 2), enhanced activity which was significantly above the control $(p=0.016)$, was measured. However, a dramatic rise in this activity was seen after $4 \mathrm{~d}$ in culture (Fig. 1, d 5). This pattern of dexamethasone

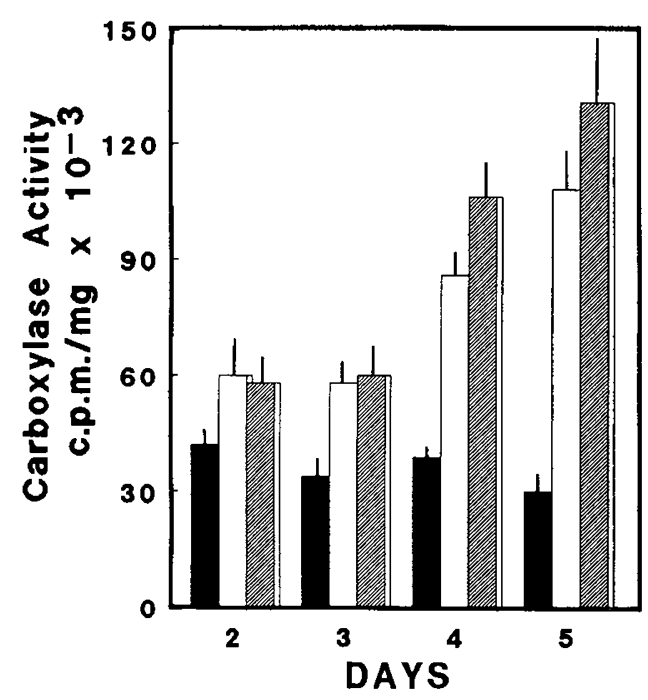

Fig. 1. $\gamma$-Carboxylase activity in cultured fetal hepatocytes treated with dexamethasone. Hepatocytes from 18-d-old rat fetuses were cultured for $5 \mathrm{~d}$ in the absence (solid bars) and presence of dexamethasone $(0.1$ $\mu \mathrm{M}$, open bars; $1 \mu \mathrm{M}$, diagonal shaded bars). Fresh medium with hormones was added to the cells each day. Cells were harvested on $\mathrm{d} 2$, 3,4 , and 5 for determination of vitamin K-dependent carboxylase activity as described in Materials and Methods. The pentapeptide FLEEL was used as substrate. The data present the average activity measured in four independent experiments $\pm \operatorname{SEM}(n=4)$. 
stimulation of carboxylase activity in fetal hepatocytes was very reproducible, and the data shown in Figure 4 represent the mean of four independent experiments. An additional experiment was also carried out where $1 \mu \mathrm{M}$ dexamethasone was added to the cell culture on $\mathrm{d} 1$, whereafter the medium was replaced every day by fresh medium containing no hormone. It was found that stimulation of carboxylase activity by dexamethasone, when added to the medium according to this protocol, was insignificantly different from the profile shown in Figure 1 where dexamethasone was added to the medium every day. There was also no difference in dexamethasone stimulation of carboxylase activity whether charcoal-treated FCS or untreated FCS was used in the culture medium. As control for the dexamethasone effect on cultured fetal hepatocytes, TAT activity in cytosol from the cultured cells was determined. As shown in Figure 2, this activity was stimulated more than 10 -fold in dexamethasone-treated cells and maximum stimulation was achieved after $2 \mathrm{~d}$ in culture (Fig. 2, d 3). As seen in Figure 1 (solid bars), there was no significant change in carboxylase activity in the control culture over the 5$\mathrm{d}$ experimental period. Because there is clearly an ongoing maturation process of the vitamin K-dependent carboxylation system in d-1 8 fetal livers, the unchanged carboxylase activities that were measured in the control fetal cells on d 2-5 indicate that these cells did not differentiate into adult hepatocytes under the conditions used for fetal hepatocyte cell culture. Additional data to support this conclusion were the findings of extremely low DT-diaphorase activities in cytosol from these cells, which is a documented characteristic of the fetal liver (7). Insulin in contrast to dexamethasone was shown in several similar experiments to have no effect on carboxylase activity in fetal hepatocytes cultured in the arginine-free medium (data not shown). Insulin was used in the concentration range $10-100 \mathrm{nM}$. The endogenous concentration of insulin in our culture medium was estimated to be $<0.01 \mathrm{nM}$. Of the cytokines, we investigated the effect of IL-1, epidermal growth factor, and platelet-derived growth factor on carboxylase activity. The growth factors did not affect carboxylase activity but a small down-regulation of the activity was observed with interleukin-1 (data not shown).

Gallaher et al. (15) reported that $\mathrm{T}_{3}$, when given to pregnant rats, stimulates the activity of the fetal lung vitamin $\mathrm{K}$-dependent carboxylation system. However, we found no effect on the vitamin K-dependent carboxylase when our fetal hepatocytes were cultured with $\mathrm{T}_{3}$. Also, $\mathrm{T}_{3}$ had no effect on the liver vitamin $\mathrm{K}$ dependent carboxylation system when the hormone was admin-

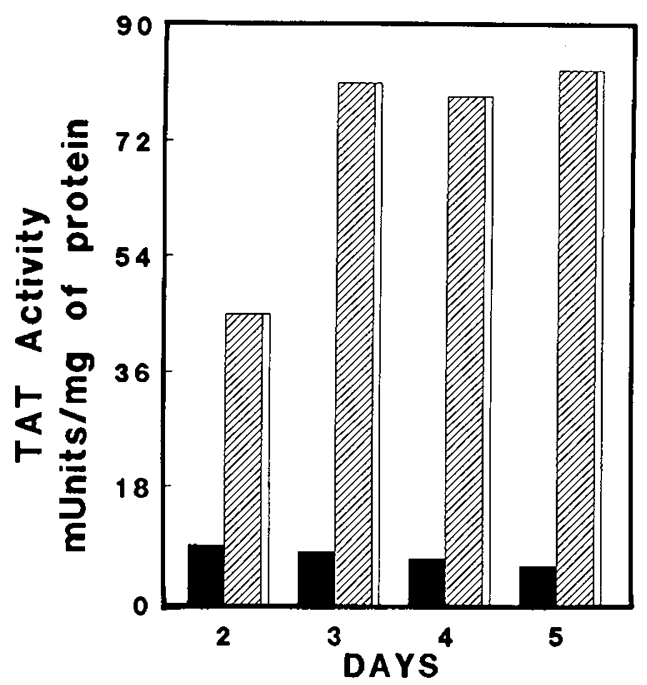

Fig. 2. TAT activity measured in cultured fetal hepatocytes treated with dexamethasone. Hepatocytes from 18-d-old rat fetuses were cultured for $5 \mathrm{~d}$ in the absence (solid bars) and presence (diagonal shaded bars) of $1 \mu \mathrm{M}$ dexamethasone. TAT activity was measured in cell cytosol as described in Materials and Methods. istered to pregnant rats by the protocol described by Gallaher et al. (15). Carboxylase activity in livers from 20-d rat fetuses obtained from mothers treated with saline (control) and $\mathrm{T}_{3}(7$ $\mathrm{mg} / 1 \mathrm{~kg}$ ) was measured to be $22000 \pm 1300$ and $21600 \pm$ $1500 \mathrm{cpm} / \mathrm{mg}$, respectively.

The quality of the fetal cell culture as a model system for the fetal liver was verified further by experiments where the anticoagulant warfarin was added to the medium. As shown in Figure 3 , warfarin $(50 \mu \mathrm{M})$ enhanced carboxylase activity about twofold when the cells were treated for $24 \mathrm{~h}$ with the drug (Fig. 3, d 2). This is consistent with what is known about the effect of the drug on the intact liver (14). The long-lasting effect of warfarin is also demonstrated in Figure 3: enhanced carboxylase activity was maintained in the cells for 3 additional d (d 3-5) after the drug was removed from the cells.

Neonatal rat. The next set of experiments was designed to test dexamethasone as a potential drug for boosting carboxylase activity in the developing liver. Included in these experiments were newborn rats treated with insulin for comparison with the cell culture data which showed no effect of insulin. Neonatal rats on the $1 \mathrm{st} \mathrm{d}$ of birth (within $24 \mathrm{~h}$ after delivery) were treated with saline (control rats), insulin, and dexamethasone, respectively. Rats were killed on d 2, 3, 5, and 7 after birth for preparation of liver microsomes and determination of carboxylase activity. The activity profiles are shown in Figure 4 for carboxylase activity determined with a synthetic peptide (panel $A$ ) and for this activity determined as $\gamma$-carboxylation of endogenous microsomal proteins (panel $B$ ). In the figure, solid bars represent control rats, open bars represent insulin-treated rats, and diagonal shaded bars represent dexamethasone-treated rats. The activity was also determined in d-21 (birth) fetuses from untreated mothers. In insulin-treated animals, the activity profile was not different from the profile in saline-treated animals. On the other hand, dexamethasone resulted in a small but significant $(p=0.0001)$ increase in activity $24 \mathrm{~h}$ after injection of the drug with a large increase in the activity measured in dexamethasonetreated animals on $\mathrm{d} 7$ after birth. The profile shown in Figure 4 has been repeated in six independent experiments. It was concluded from these experiments that the dexamethasone effect on carboxylase activity in fetal hepatocytes in culture indeed is

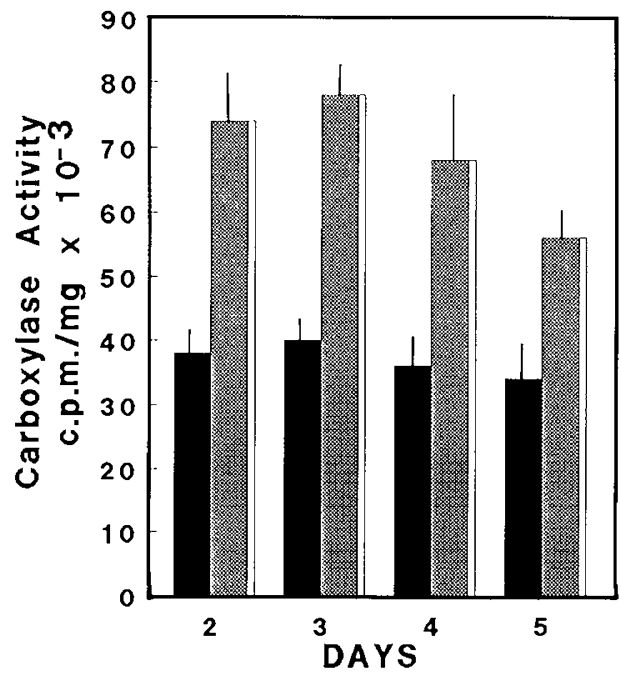

Fig. 3. $\gamma$-Carboxylase activity in cultured fetal hepatocytes treated with warfarin. Hepatocytes from 18-d-old rat fetuses were cultured for 5 $\mathrm{d}$ in the absence (solid bars) and presence (dotted shaded bars) of $50 \mu \mathrm{M}$ warfarin. Warfarin was added to the cell medium on $\mathrm{d} 1$, whereafter the medium was replaced each day by fresh medium containing no drug. Cells were harvested on $\mathrm{d} 2,3,4$, and 5 for determination of carboxylase activity. The pentapeptide FLEEL was used as substrate. The data are presented as the average activity measured in three independent experiments $\pm \operatorname{SEM}(n=3)$. 


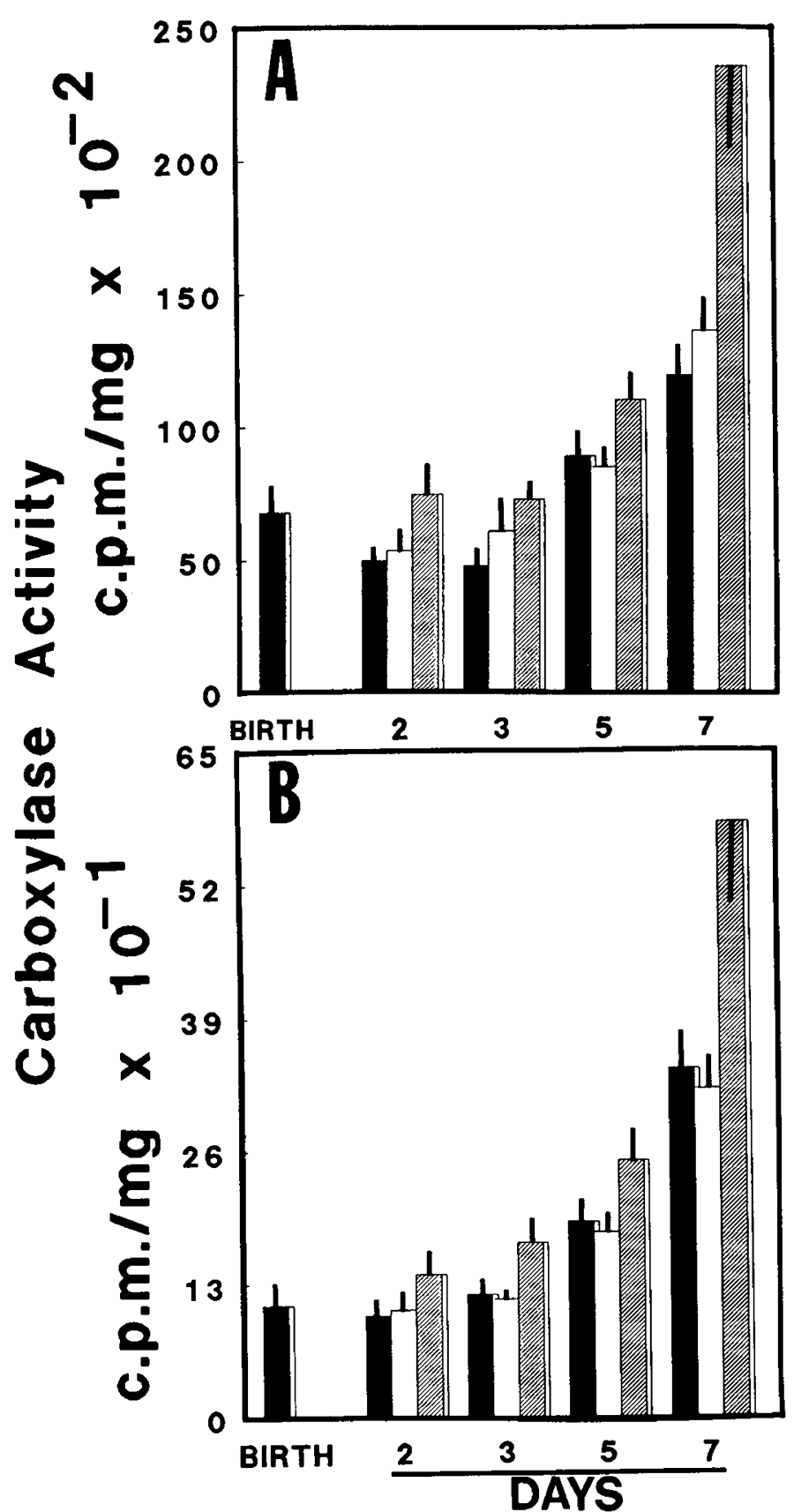

Fig. 4. $\gamma$-Carboxylase activity in liver microsomes from neonatal rats treated with insulin and dexamethasone. Neonatal rats on the 1 st $\mathrm{d}$ of birth (within $24 \mathrm{~h}$ after delivery) were treated with saline (solid bars), insulin (40 U per rat) (open bars) and dexamethasone ( $10 \mu \mathrm{g} / \mathrm{g}$ body wt) (diagonally shaded bars). Rat pups killed at birth (birth) and neonatal rats sacrificed on $\mathrm{d} 2,3,4,5$, and 7 after birth were used for preparation of liver microsomes and determination of carboxylase activity as described in Materials and Methods. The activity profiles shown in panels $A$ and $B$ are for the activity determined with the FLEEL peptide and endogenous microsomal proteins, respectively, as carboxylase substrates. The data are presented as the average activity measured in six independent experiments $\pm \operatorname{SEM}(n=6)$.

reflected in the intact animal. As seen with the cell culture experiments, a delayed large response to dexamethasone was also observed in the intact animal.

Increased carboxylase activity is also associated with vitamin $\mathrm{K}$ deficiency and after anticoagulation with warfarin (10). In these cases, it has been found that the intracellular concentration of the vitamin K-dependent clotting factor precursors increases in a parallel manner with carboxylase activity $(10,12)$. Because most of these studies have been conducted with the prothrombin precursor, the prothrombin precursor concentration was measured in microsomes from the neonatal rats treated with saline, insulin, and dexamethasone. As shown in Figure 5, there was no difference in prothrombin precursor concentration in microsomes from saline (solid bars), insulin-treated (open bars), or dexamethasone-treated (diagonal bars) neonatal rats.

An additional observation was made which may aid in determining the mechanism of action of dexamethasone on carboxylase activity. This observation is interesting in light of the previous finding that microsomal membranes from warfarintreated rats show enhanced $\left[{ }^{14} \mathrm{C}\right] \gamma$-carboxylation of the endogenous factor $X$ precursor pool but not the endogenous prothrombin precursor pool (12). We carried out similar vitamin Kdependent labeling experiments with microsomal membranes isolated from the 7-d-old neonatal rats treated with saline, insulin, and dexamethasone. As shown in Figure 6 (panel A, lane 3), dexamethasone also results in enhanced labeling of the membrane-bound factor X precursor pool which is demonstrated on the fluorogram in Figure 6 by the $70-\mathrm{kD}$ band. The identity of the factor $X$ precursor was established with factor $X$ antibodies. Lanes 1 and 2 (Fig. 6A) have proteins from neonatal rats treated with insulin and saline, respectively. As shown, insulin had no effect on labeling of the 70-kD factor X precursor pool. Labeling of the membrane-bound prothrombin precursor pool, as shown by labeling of the $78-\mathrm{kD}$ prothrombin precursor in Figure $6(12)$, was not affected by the hormones. This effect of dexamethasone could also be demonstrated in fetal hepatocytes treated in culture for $5 \mathrm{~d}$ with dexamethasone. As shown in Figure $6 \mathrm{~B}$, labeled microsomes from dexamethasone-treated cells clearly demonstrated enhanced labeling of the factor $\mathrm{X}$ precursor pool (lane 1). Lane 2 (Fig. $6 B$ ) has labeled proteins from untreated cells. The $36-\mathrm{kD}$ protein has not yet been identified.

\section{DISCUSSION}

This report demonstrates that dexamethasone affects the vitamin K-dependent carboxylation system in cultured fetal hepatocytes and neonatal rat liver by producing a higher $\gamma$-carboxylation activity. Stimulation of this activity by the drug was clearly delayed when compared with its stimulation of TAT activity, the enzyme activity traditionally used to monitor enzyme induc-

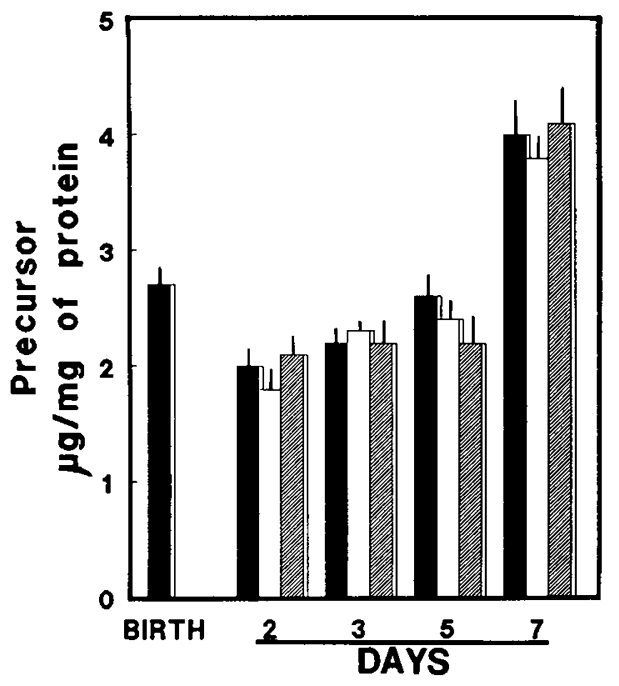

Fig. 5. Prothrombin precursor concentration in liver microsomes from neonatal rats treated with insulin and dexamethasone. The prothrombin precursor concentration was determined in microsomes obtained from the experiment described in the legend to Figure 4. The precursor concentration was estimated by immunodot blotting with purified rat prothrombin as standard (see Materials and Methods). 

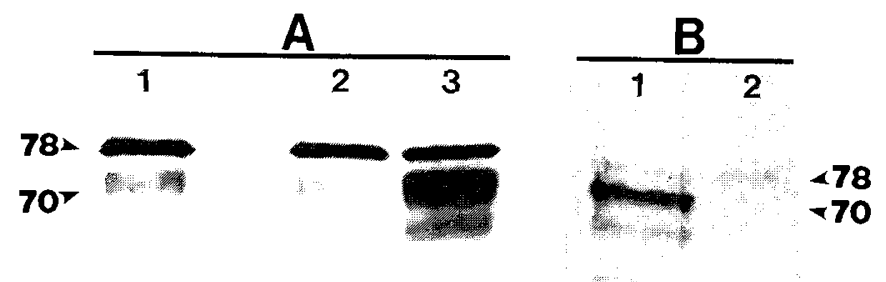

36
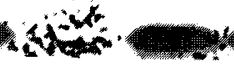

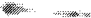

Fig. 6. Vitamin K-dependent ${ }^{14} \mathrm{C}$ labeling of carboxylase substrates attached to the microsomal membrane. Liver microsomal membranes were prepared from 7-d-old neonatal rats that had been injected with insulin, saline, and dexamethasone by the protocol described in the legend to Figure 4. These membranes were subjected to vitamin $\mathrm{K}$ dependent $\left[{ }^{14} \mathrm{C}\right] \gamma$-carboxylation, SDS-PAGE, and fluorography as described in Materials and Methods. The SDS-PAGE fluorograms of membranes from saline, insulin-, and dexamethasone-treated animals are shown in panel $\mathrm{A}$ (lanes 1,2 , and 3, respectively). Vitamin $\mathrm{K}$ dependent ${ }^{14} \mathrm{C}$-labeled microsomal membrane fragments from fetal hepatocytes treated for $5 \mathrm{~d}$ with $1 \mu \mathrm{M}$ dexamethasone and saline are shown in panel B, lanes 1 and 2, respectively. Molecular masses of radiolabeled proteins in kilodaltons are indicated in the figure.

tion by dexamethasone. The delayed response was also measured in intact animals, which showed that the cell culture data indeed were reflected in vivo. The data may indicate that intermediate factors are involved in induction of carboxylase activity by dexamethasone, a possibility that is currently being investigated in our laboratory.

Our laboratory has shown previously (7) that $\gamma$-carboxylation in rat livers is down-regulated shortly after birth whereas $\gamma$ carboxylation reaches adult levels in $7-d$ neonatal rats. The mechanism behind the transient down-regulation of activity is unknown but coincides with the dramatic hormonal changes that occur around birth. The fall in plasma insulin concentration that occurs at birth has been shown to modulate expression of several enzymes in the developing liver (16). On the basis of our data, however, insulin does not appear to be implicated in regulation of carboxylase activity. As shown, insulin addition to the cell culture or injection in neonatal rats resulted in no change in this activity from the activity measured in the saline control. Because our culture medium did contain insulin, although in a very low concentration $(<0.01 \mathrm{nM})$, the possibility cannot be excluded that the endogenous insulin maintained the carboxylase in an already activated stage and thus was responsible for the apparent lack of an effect of added insulin. In support of our conclusion, however, findings made by others (17) show that insulin, when added to fetal hepatocytes under very similar culture conditions, does exert regulatory effects on these cells.

If $\gamma$-carboxylation of vitamin K-dependent clotting factors is a key regulatory element in output of these proteins from liver to blood, as has been suggested by other research $(4,18,19)$, factors that modulate this activity could possibly be used to control the hemostatic mechanism. Our finding that dexamethasone increases the $\gamma$-carboxylation potential of the fetal and neonatal liver should indeed inspire further research on the effect this drug has on the developing hemostatic system. Certainly, the effect of dexamethasone on maturation of the surfactant system in the developing lung was an important finding for prevention of respiratory distress in premature infants.

We also show in this work that dexamethasone results in enhanced ${ }^{14} \mathrm{C}$ labeling of the intracellular factor $\mathrm{X}$ precursor pool in the microsomal membrane, a finding which recently also has been made with warfarin-treated rats (12). This was an unexpected finding because the two drugs are known to have quite different effects in vivo. Warfarin in contrast to dexamethasone is an anticoagulant that inhibits the vitamin $\mathrm{K}$ cycle in liver (10). The mechanisms by which dexamethasone and warfarin both "turn on" $\left[{ }^{14} \mathrm{Cl} \gamma\right.$-carboxylation of the membrane-associated factor $\mathrm{X}$ precursor pool in rat liver have not yet been elucidated.

It is a well-established observation that warfarin also results in enhanced $\gamma$-carboxylation activity in liver and other tissues. Enhanced $\gamma$-carboxylase activity in rat liver induced by warfarin is always found associated with an increase in the intracellular prothrombin precursor concentration which, on the other hand, was not found when rats were treated with dexamethasone. This finding, together with recent data from our laboratory showing that the dexamethasone effect on carboxylase activity is mediated by the glucocorticoid receptor (unpublished data), certainly suggest that the two drugs induce carboxylase activity by different mechanisms. Dexamethasone may indeed regulate $\gamma$-carboxylase activity at the transcriptional level.

Acknowledgment. The authors thank Angela Higgins for typing the manuscript.

\section{REFERENCES}

1. Lane PA, Hathaway WE 1985 Vitamin K in infancy. J Pediatr 106:351-359 2. Yang Y-M, Simon N, Maertens P, Brigham S, Liu P 1989 Maternal-fetal transport of vitamin $K_{1}$ and its effects on coagulation in premature infants. J Pediatr 115:1009-1013

3. Kazzi NJ, Ilagan NB, Liang K-C, Kazzi GM, Poland RL, Grietsell LA, Fujii Y, Brans YW 1989 Maternal administration of vitamin K does not improve the coagulation profile of preterm infants. Pediatrcis 84:1045-1050

4. Mandelbrot L, Guillaumont $M$, Leclercq $M$, Lefrene JJ, Gozin D, Daffos $F$, Forestier F 1988 Placental transfer of vitamin $K_{1}$ and its implications in fetal hemostasis. Thromb Haemost 60:39-43

5. Kris RV, Shearer JM, Göbel V 1988 Vitamin K in infancy. Eur J Pediatr 147:106-112

6. Allan WC, Volde JJ 1986 Periventricular-intraventricular hemorrhage. Pediatr Clin North Am 36:47-63

7. Wallin R 1989 Vitamin K-dependent carboxylation in the developing rat: evidence for a similar mechanism of action of warfarin in fetal and adult livers. Pediatr Res 26:370-376

8. Furie B, Furie BC 1988 The molecular basis of blood coagulation. Cell 53:505518

9. Suttie JW, Jackson CM 1977 Prothrombin structure activation and biosynthesis. Physiol Rev 57:1-70

10. Suttie JW 1985 Vitamin K-dependent carboxylase. Annu Rev Biochem 54:459-477

11. Wallin R, Martin LF 1987 Warfarin poisoning and vitamin K antagonism in rat and human liver: design of a system in vitro that mimics the system in vivo. Biochem J 240:389-396

12. Wallin R, Martin LF 1988 Early processing of prothrombin and factor $X$ by the vitamin K-dependent carboxylase. J Biol Chem 263:9994-10001

13. Granner DK, Tomkins GM 1970 Tyrosine aminotransferase (rat liver). Methods Enzymol 17:633-637

14. Sadowski JA, Esmon CT, Suttie JW 1976 Vitamin K-dependent carboxylase Requirements of the rat liver microsomal enzyme system. J Biol Chem 251:2770-2776

15. Gallaher KJ, Rannels DE, Rannels SR 1989 Vitamin K-dependenton carboxylase activity in fetal rat lung: developmental effects of dexamethasone and triiodothyronine. Pediatr Res 25:530-534

16. Böhare HJ, Sparmann G, Hofmann E 1983 Biochemistry of liver development in the perinatal period. Experentia 38:473-482

17. Cane MH, Ho KKW, Shelly L, Milward E, Yeoh GCT 1989 Insulin antagonism of dexamethasone induction of tyrosine aminotransferase in cultured fetal hepatocytes. Eur J Biochem 182:429-435

18. Hassan HJ, Leonardi A, Chelucci C, Mattia G, Macioce G, Guerriero R, Russo G, Mannucci PM, Peschle C 1990 Blood coagulation factors in human embryonic-fetal development: preferential expression of the FVII/tissue factor pathway. Blood 76:1158-1164

19. Forestier F, Daffos F, Rainaut M, Sole Y, Amiral J 1985 Vitamin K dependent proteins in fetal hemostasis at trimester of pregnancy. Thromb Haemost 53:401-403 